\title{
LONGEVIDADE DE SEMENTES DE CAMU-CAMU SUBMETIDAS A DIFERENTES AMBIENTES E FORMAS DE CONSERVAÇÃ ${ }^{1}$
}

\author{
KAORU YUYAMA², NALU BANDEIRA MENDES ${ }^{3}$, JOÃO PEDRO VALENTE $^{4}$
}

RESUMO-O camu-camu (Myrciaria dubia (H.B.K.) McVaugh) produz fruto com grande potencial para extração de ácido ascórbico, que apresenta relevante importância econômica e social, com inúmeras aplicações industriais. O objetivo deste trabalho foi avaliar o efeito de diferentes formas de conservação e ambientes de armazenamento, sobre a manutenção da viabilidade das sementes. O delineamento experimental inteiramente casualizado, utilizando parcelas subsubdivididas, onde os fatores foram: ambiente de armazenamento (ao ar livre, em água, em câmara a 5 e a $10^{\circ} \mathrm{C}$ ), forma de conservação (sementes com polpa - CP, sementes sem polpa - SP e sementes lavadas e tratadas - LT) e período de armazenamento ( $0 ; 2 ; 4$ e 6 meses). O critério de avaliação adotado foi a protrusão da raiz primária. As sementes armazenadas em água, nas formas SP e LT, apresentaram germinação maior que 90\%. As sementes nas formas CP e LT, armazenadas a 5 e a 10 ${ }^{\circ} \mathrm{C}$, tiveram germinação acima de $89 \%$. O armazenamento em água e ao ar livre não afetou a germinação, podendo as sementes serem armazenadas durante o período de seis e quatro meses, respectivamente. As sementes CP, armazenadas em água, tiveram menor tempo médio para germinação. O índice de velocidade de germinação aumentou com o período de armazenamento e foi maior nas sementes armazenadas na água em todos os períodos. As sementes com polpa apresentaram menor índice de velocidade de germinação em todo o período de armazenamento avaliado.

Termos para indexação: Myrciaria dubia, armazenamento, germinação.

\section{LONGEVITY CAMU-CAMU SEEDS SUBMITTED TO DIFFERENT STORAGE ENVIRONMENT AND FORMS OF CONSERVATION}

\begin{abstract}
Camu-camu (Myrciaria dubia (H.B.K.) McVaugh) contains great potential for ascorbic acid extraction, which has economic and social importance, with innumerable industrial applications. The objective of this work was to evaluate the effect of different storage environment and forms of conservation for maintaining the viability of camu-camu seeds. The experimental design was randomized blocks design in split-split plot, with the following factors: storage conditions (natural, in water, in cold chamber $5-10$ ${ }^{\circ} \mathrm{C}$ ), conservation form (seeds with pulp - CP, seeds without pulp - SP and seeds washed and treated - LT) and storage time ( $0,2,4$ and 6 months). The evaluation criterion adopted was the protrusion of the primary root. The seeds SP and LT storage in water presented germination upper than $90 \%$. The seeds CP and LT storage at 5 and $10{ }^{\circ} \mathrm{C}$ had germination upper than $89 \%$. The storage in water and in natural condition did not affect the germination, being able to be storage in a period of six and four months respectively. The CP seeds storage in water had the shortest time of germination. The germination speed index increased with the period of storage and was larger for seeds storage in water for all the periods. The seeds with pulp presented minor germination speed index in the whole period of storage evaluated.
\end{abstract}

Index terms: Myrciaria dubia, storage, germination.

\footnotetext{
${ }^{1}$ (Trabalho 109-10). Recebido em: 03-05-2010. Aceito para publicação em: 03-03-2011.Parte da dissertação de mestrado, do segundo autor.

${ }^{2}$ Dr. Bolsista do CNPq, Pesquisador do Instituto Nacional de Pesquisas da Amazônia, Caixa postal $n^{\circ} 478$, CEP 69.060-001. Manaus - AM. E-mail: kyuyama@inpa.gov.br.

${ }^{3}$ MSc. Rua Rondônia, B1 29 apto 1 Conj. Eldorado, Manaus - AM.

${ }^{4}$ Dr. Docente do Curso de Agronomia da Universidade Federal de Mato Grosso. Av. Fernando Correa da Costa, 2367, Boa Esperança, CEP 78.060-90 Cuiabá - MT. E-mail: valente@ufmt.br
} 


\section{INTRODUÇÃO}

O camu-camu (Myrciaria dubia (H.B.K) Mc Vaugh) pertence à família Myrtaceae, ocorre principalmente nas margens de rios e lagos da Amazônia e tem despertado grande interesse em diversos países pelo seu potencial de produção de ácido ascórbico, que varia de 845 a $6.100 \mathrm{mg}$ em $100 \mathrm{~g}$ de polpa integral (YUYAMA et al., 2002), superior ao da maioria de plantas cultivadas (ANDRADE et al., 1995).

O grande potencial do camu-camu é sua utilização no preparo de alimentos, produzindo sorvetes de excelente sabor, contendo $450 \mathrm{mg}$ de vitamina $\mathrm{C}$ em $100 \mathrm{~g}$ de sorvete e geleia com 710 a $1.680 \mathrm{mg}$ de vitamina C por 100g (ROCA, 1965). Constitui-se também em matéria-prima para a indústria de cosméticos, química, farmacológica, conservante de alimentos e elaboração de bebidas gasosas (CORREA, 2000). A casca pode ser aproveitada para corante; e a semente, para a produção de mudas.

O principal procedimento para se determinar o comportamento de sementes no armazenamento é verificar sua tolerância ou sensibilidade ao dessecamento (HONG; ELLIS, 1996). Quando ocorre o dessecamento de uma semente recalcitrante, rapidamente se reduz sua viabilidade e vigor, e perde completamente sua capacidade germinativa. Todavia, não é conhecido o mecanismo pelo qual a semente recalcitrante é sensível à perda de umidade, tampouco, dispõe-se de processos adequados à conservação deste tipo de semente.

O camu-camu, dependendo da umidade da semente, pode perder rapidamente sua capacidade germinativa, e poucos são os estudos sobre o comportamento das sementes durante o armazenamento, visando a manter sua viabilidade por longo tempo (CALZADA, 1979/80).

A sensibilidade ao dessecamento constitui um dos fatores relacionados à rápida perda de viabilidade das sementes de camu-camu, pois não toleram dessecamento e umidade abaixo de $20 \%$; portanto, são enquadradas na categoria de sementes recalcitrantes, segundo a classificação de Roberts (1973).

O presente trabalho teve como objetivo avaliar o efeito de diferentes formas de conservação e ambientes de armazenamento sobre a manutenção da viabilidade das sementes de camu-camu por um período de seis meses.

\section{MATERIAL E MÉTODOS}

O experimento foi realizado no Laboratório de Semente da Faculdade de Ciências Agrárias da Universidade Federal do Amazonas e na Coordenação de Pesquisas em Ciências Agronômicas do Instituto Nacional de Pesquisa da Amazônia.

Os frutos foram coletados em plantas da Fazenda Yuricam, localizada no km-100 da Rodovia Estadual AM 010, no município de Rio Preto da Eva, AM.

As sementes foram separadas em três lotes: a) sementes com mucilagem ou resíduo de polpa (CP); b) sementes sem polpa lavadas em água corrente (SP), e c) sementes lavadas e tratadas com solução de hipoclorito de sódio a $10 \%$ por 15 minutos (LT). As sementes não foram submetidas a secagem antes do armazenamento.

O armazenamento de sementes foi realizado nas seguintes condições: a) ambiente natural dentro dos sacos plásticos; b) dentro da água, em um balde de 5 litros, sendo realizada a cada dois dias a troca da água; c) câmara fria a $5^{\circ} \mathrm{C}$, e d) câmara fria a 10 ${ }^{\circ} \mathrm{C}$. Nas câmaras frias, as sementes foram colocadas dentro de sacos plásticos, e a umidade relativa foi mantida a $45 \%$.

$\mathrm{O}$ armazenamento em ambiente natural consistiu em manter as sementes a uma temperatura média entre $24-30{ }^{\circ} \mathrm{C}$ e umidade relativa do ar entre $89-91 \%$. Neste ambiente, as condições de temperatura e umidade variaram durante o dia e a noite, em função das condições climáticas da região. As sementes foram embaladas em sacos plásticos transparentes e, em seguida, colocados em saco preto de polietileno de $10 \mathrm{~kg}$.

Para a determinação do teor de água, as sementes foram dessecadas em estufa de secagem e esterilização FANEM ${ }^{\circledR}$ Mod. $315 \mathrm{SE}$, à temperatura de $105^{\circ} \mathrm{C}$, por 24 horas, de acordo com as recomendações das Regras para Análise de Sementes (BRASIL, 1992). A umidade foi verificada no início e durante o tempo de armazenamento e, a cada sessenta dias foram retiradas amostras de sementes armazenadas em cada um dos ambientes de armazenamento para avaliações dos teores de água.

$\%$ Teor de água $=\left(\frac{\text { Peso úmido }- \text { Peso seco }}{\text { Peso seco }}\right) \times 100$

Nos estudos da germinação, as sementes foram colocadas para germinar em câmara de germinação de marca FANEM ${ }^{\circledR}$ Mod. 347CDG, com fotoperíodo de 12 horas contínuas. Os testes de germinação foram realizados à temperatura constante 
de $30^{\circ} \mathrm{C}$. As sementes foram semeadas em recipiente de vidro tipo "pirex" e bandejas plásticas, contendo uma camada de $3 \mathrm{~cm}$ do substrato vermiculita esterilizada e umedecida com água destilada. As bandejas foram mantidas em sacos plásticos, visando à manutenção da umidade. As sementes foram distribuídas a uma distância de $2 \mathrm{~cm}$ entre a fileira e $3 \mathrm{~cm}$ dentro das linhas, a uma profundidade de 0,5 $\mathrm{cm}$. O critério de avaliação adotado foi a protrusão da raiz primária.

Odelineamento experimental foi o inteiramente casualizado, em parcelas subsubdivididas, com quatro repetições de 25 sementes por subsubparcela. Os fatores foram: ambientes de armazenamento (natural, água, câmara fria a 5 e $10^{\circ} \mathrm{C}$ ), formas de conservação (sementes sem polpa, sementes com polpa e sementes lavadas/tratadas) e o período de armazenamento ( 0 ; 2; 4 e 6 meses).

Os parâmetros avaliados foram a porcentagem de germinação, conforme Regras para Análise de Sementes (BRASIL, 1992), o índice de velocidade de germinação (IVG), segundo o método descrito por Maguire (1962), e o tempo médio de germinação. O tempo médio foi calculado da seguinte forma: $\mathrm{t}=\Sigma$ niti/ $/$ ni. Em que ni $=$ número de sementes germinadas por dia, e ti = tempo de incubação (dias).

Os resultados foram submetidos à análise de variância, pelo teste $\mathrm{F}$, e as médias, comparadas pelo teste de Tukey, ao nível de $5 \%$ de probabilidade (GOMES, 1982).

\section{RESULTADOS E DISCUSSÃO}

O teor de água da semente, submetida a diferentes ambientes de armazenamento, formas de conservação, período de armazenamento e suas interações (forma $\mathrm{x}$ ambiente, forma $\mathrm{x}$ período e ambiente x período), apresentou diferenças significativas (Tabela 1). A umidade da semente oscilou entre 45 e $56 \%$, não afetando a germinação. Ferreira e Gentil (2003), estudando o comportamento de sementes de camu-camu durante o armazenamento, observaram uma redução de $46 \%$ para $40 \%$ do teor de água, fator este que afetou significativamente a viabilidade e o vigor das sementes armazenadas, diferindo dos resultados encontrados neste experimento.

Segundo Yap (1981), citado por Aguiar et al. (1993), o excesso de umidade causa infestação por fungos nas sementes, levando à redução da viabilidade. Portanto, a morte de algumas sementes, de certa forma,foi influenciada pela infestação por fungos, que podem ter acarretado a perda da viabilidade de sementes, apesar de terem sido tratadas com ácido ascórbico, cujo pH é menor que 3,0, o que lhe confere ação fungicida.

Ocorreram diferenças significativas nas porcentagens, tempo e índice de velocidade de germinação das sementes para os ambientes de armazenamento, formas de conservação e período de armazenamento. As maiores porcentagens de germinação foram obtidas em ambiente natural e em água, com valores de 95,1 e 97,6\%, respectivamente. Entre as formas de conservação, as sementes sem polpas (SP) e lavadas e tratadas (LT) apresentaram maiores taxas de germinação, ambas com $93,7 \%$. Nos períodos de zero, 2 e 4 meses, foram observadas as maiores porcentagens de germinação (Tabela 1).

Observou-se que o tempo médio de germinação das sementes foi menor em água (19,25 dias), seguida de câmara a $5{ }^{\circ} \mathrm{C}$ e natural $(30,08$ e 32,50 , respectivamente), e maior em câmara a $10^{\circ} \mathrm{C}(39,47$ dias). Entre as formas de conservação, verificou-se que o tempo médio de germinação em SP $(33,10$ dias) diferiu significativamente de CP (27,50 dias); entretanto, LT (30,37 dias) não diferiu significativamente de SP e CP. O período de armazenamento foi inversamente proporcional ao tempo de germinação das sementes. Isto é, a semente de camu-camu não suporta grande período de armazenamento, típico de semente recalcitrante.

Em relação ao ambiente de armazenamento, o índice de velocidade de germinação foi maior em água, seguida de natural, câmara a 5 e $10{ }^{\circ} \mathrm{C}$. O índice de velocidade de germinação aumentou com o período de armazenamento (Tabela 3 ), e foi maior nas sementes conservadas SP e LT (Tabela 1).

Na interação, verificou-se que, dentro da forma de conservação SP e LT, o armazenamento em água foi superior no percentual de germinação em relação à câmara a $10^{\circ} \mathrm{C}$ (Tabela 3 ). Armazenamento no ambiente natural e na água não apresentou diferença significativa entre as formas de conservação. As maiores porcentagens de germinação, após 6 meses de armazenamento, foram obtidas nas sementes SP e LT: 93,5 e 94,3\%, respectivamente. Nestas duas formas de conservação, a porcentagem de germinação mostrou uma tendência de aumento com o tempo de armazenamento, e no CP ocorreu o contrário (Tabela 2).

Nas diferentes formas de conservação, as sementes SP, CP e LT, no ambiente água, apresentaram os menores tempos de germinação: 24,64; 17,28 e 15,82 dias, respectivamente (Tabela 2).

Com 0 mês de armazenamento, o tempo médio de germinação em SP foi mais lento do que em CP e LT. Com 2 meses de armazenamento, 
as sementes SP apresentaram tempo médio de germinação mais lento do que as sementes CP. Aos 4 e 6 meses, não houve diferença significativa entre as médias. Para todas as formas de conservação, aos 4 e 6 meses de armazenamento, as sementes apresentaram tempo médio de germinação menor do que com zero e dois meses (Tabela 2).

Ocorreram diferenças significativas entre os ambientes de armazenamento e as formas de conservação para o índice de velocidade da germinação das sementes. O índice de velocidade de germinação foi maior no armazenamento em água para todas as formas de conservação. Não houve diferença em função das formas de conservação nos ambientes de água e natural. Nas câmaras a 5 e a $10{ }^{\circ} \mathrm{C}$, verificou-se para as sementes $\mathrm{CP}$ uma velocidade de germinação menor (Tabela 2). Estes resultados confirmam os obtidos por Ferreira e Gentil (2003), que afirmaram que a emergência e o vigor das sementes de camu-camu não são afetados durante o armazenamento (período de 150 dias); armazenados em ambiente natural, aos 10 e $20{ }^{\circ} \mathrm{C}$ na semente SP.

Quanto ao índice de velocidade de germinação das sementes em relação às formas $\mathrm{e}$ aos períodos de armazenamento, verificou-se que, no período 0 , não houve diferença significativa entre formas de conservação. Já aos 2; 4 e 6 meses, os índices obtidos com as sementes SP e LT foram significativamente maiores que nas sementes $\mathrm{CP}$ (Tabela 2). Nas diferentes formas de conservação, o índice de velocidade de germinação aumentou até os 4 meses e tendeu a estabilizar-se aos 6 meses.

No desdobramento para ambientes de armazenamento, nos períodos de armazenamento, verificou-se que, no tempo zero, não houve diferença significativa. $\mathrm{O}$ armazenamento em água por 2 meses apresentou maior germinação que os demais ambientes. Já aos 4 meses, ambiente natural e em água apresentaram maiores percentuais de germinação. No ambiente natural, aos 6 meses, não havia mais sementes para os testes de germinação, pois as mesmas já estavam todas germinadas. No ambiente de armazenamento, as sementes mantidas em água apresentaram uma taxa de germinação acima de $99 \%$ aos 2 meses e, posteriormente, aos $100 \%$, superando os demais tratamentos (Tabela 3). Este resultado concorda com Villachica (1996) que, estudando a conservação de sementes de camucamu, verificou que os resultados de germinação, após seis meses de armazenamento em água, não afetaram a viabilidade das sementes.

A porcentagem de germinação no ambiente natural foi crescente no decorrer do período de armazenamento e, antes de atingir 6 mês, $100 \%$ de sementes estavam germinadas. Por outro lado, em câmaras a 5 e $10{ }^{\circ} \mathrm{C}$, registrou-se um decréscimo gradual na taxa de germinação ao longo do período, porém a $10{ }^{\circ} \mathrm{C}$ foi superior a de $5{ }^{\circ} \mathrm{C}$ (Tabela 3 ).

A água é o fator que mais influencia no processo de germinação, porque as propriedades da água influenciam profundamente na estrutura e nas outras constituintes celulares essenciais à vida. Resultados obtidos neste experimento mostraram que as sementes conservadas em água por 180 dias mantiveram poder germinativo de $100 \%$, sendo que, a partir do $4^{\circ}$ mês, ocorreu o aceleramento do processo germinativo das sementes (protrusão da raiz primária). O camu-camu é uma espécie nativa das margens de rios e lagos, portanto este tratamento não é um dos mais recomendados para o armazenamento das sementes, pois ocorre o início do processo de germinação ao longo do armazenamento.

Avaliando as sementes armazenadas em ambiente natural, verificou-se que, apesar de permanecerem acondicionadas em sacos plásticos, as mesmas iniciaram o processo germinativo. Este resultado indicou que sementes embaladas em sacos plásticos à temperatura ambiente têm sua germinação induzida pela alta umidade e pela temperatura, que é adequada para sementes tropicais, como a pupunheira (VILLACHICA, 1996); este tipo de armazenamento consiste em um método pré-germinativo.

As sementes mantidas em sacos plásticos no ambiente natural apresentaram porcentagem de germinação entre 88 a 99\% (Tabela 3). Em estudo feito por Gentil e Ferreira (2000), eles observaram que o acondicionamento em saco plástico e o armazenamento à temperatura ambiente e a $20^{\circ} \mathrm{C}$ podem conservar as sementes de camu-camu por um período de até 6 meses.

Ao longo do tempo, algumas sementes apresentaram alto índice de germinação logo depois de serem retiradas das câmaras a 5 e $10^{\circ} \mathrm{C}$, indicando que a alta taxa de germinação foi favorecida pela mudança brusca de temperatura, ou seja, a saída de uma temperatura baixa para uma alta $\left(30{ }^{\circ} \mathrm{C}\right)$, o que pode ter provocado a quebra de dormência pelo choque térmico. Constatou-se, ainda, que no armazenamento em câmara fria, poucas foram as sementes que não germinaram; contudo, após a protrusão da raiz primária, provavelmente, em função da baixa temperatura, as mesmas não resistiram e morreram.

Quanto ao período de armazenamento, as sementes armazenadas em água apresentaram um tempo médio de germinação menor do que os demais ambientes de armazenamento, em 0 e 2 meses, e no 
período de 4 e 6 meses mostraram tendência de menor tempo médio (Tabela 3 ), seguida de armazenamento natural e em câmara a $5{ }^{\circ} \mathrm{C}$, sendo a mais longa em câmara a $10{ }^{\circ} \mathrm{C}$, aos 2 meses. Dentro de cada ambiente, em geral, ocorreu diminuição no tempo médio de germinação com o decorrer do tempo (Tabela 3).

Mesmo sendo submetidas a baixas temperaturas, as sementes de camu-camu mantiveram seu poder germinativo durante os períodos de armazenamento. $\mathrm{O}$ mesmo foi observado por Ferreira e Gentil (2003) por um período de 5 meses.

Os índices de velocidade de germinação foram maiores após 4 e 6 meses de armazenamento; entretanto, nas sementes armazenadas em água, foi maior em todos os períodos de armazenamento (Tabela 3).
Em todos os ambientes estudados, os índices de velocidade de germinação aumentaram até o quarto mês e mostraram tendência de diminuição aos 6 meses (Tabela 3), concordando com resultados encontrados por Andrade e Pereira (1997), segundo os quais o processo de deterioração das sementes é seguido normalmente pela redução na velocidade de germinação.

As sementes mantidas em câmaras frias conservaram a viabilidade durante o período de armazenamento, mas apresentaram os menores índices de velocidade de germinação aos 4 e 6 meses (Tabela 3). O armazenamento das sementes em câmara a $10{ }^{\circ} \mathrm{C}$ foi o menos eficiente, tendo em vista ter apresentado menor vigor em todos os períodos de armazenamento, com exceção do tempo zero.

TABELA 1 - Porcentagem, tempo e índice de velocidade de germinação das sementes de camu-camu em função de formas de conservação, ambiente e período de armazenamento obtido em Manaus $-\mathrm{AM}$.

\begin{tabular}{|c|c|c|c|c|}
\hline & & $\begin{array}{c}\text { Porcentagem } \\
\text { de germinação } \\
(\%)\end{array}$ & $\begin{array}{c}\text { Tempo de } \\
\text { germinação } \\
\text { (dias) }\end{array}$ & $\begin{array}{c}\text { Índice de } \\
\text { velocidade de } \\
\text { germinação }\end{array}$ \\
\hline \multirow{3}{*}{ Formas de conservação } & SP & $93,7 \mathrm{a}$ & $33,10 \mathrm{a}$ & $2,61 \mathrm{a}$ \\
\hline & $\mathrm{CP}$ & $78,1 \mathrm{~b}$ & $27,50 \mathrm{~b}$ & $1,88 \mathrm{~b}$ \\
\hline & LT & $93,7 \mathrm{a}$ & $30,37 \mathrm{ab}$ & $2,75 \mathrm{a}$ \\
\hline \multirow{4}{*}{ Ambiente de armazenamento } & Natural & $95,1 \mathrm{a}$ & $32,50 \mathrm{~b}$ & $2,38 \mathrm{~b}$ \\
\hline & Água & $97,6 \mathrm{a}$ & $19,25 \mathrm{c}$ & $3,67 \mathrm{a}$ \\
\hline & $5^{\circ} \mathrm{C}$ & $76,8 \mathrm{c}$ & $30,08 \mathrm{~b}$ & $1,99 \mathrm{c}$ \\
\hline & $10^{\circ} \mathrm{C}$ & $84,5 \mathrm{c}$ & $39,47 \mathrm{a}$ & $1,63 \mathrm{~d}$ \\
\hline \multirow{4}{*}{$\begin{array}{l}\text { Período de armazenamento } \\
\text { (mês) }\end{array}$} & 0 & $90,1 \mathrm{a}$ & $74,77 \mathrm{a}$ & $0,64 \mathrm{c}$ \\
\hline & 2 & $89,2 \mathrm{a}$ & $24,57 \mathrm{~b}$ & $1,74 \mathrm{~b}$ \\
\hline & 4 & $90,3 \mathrm{a}$ & $12,06 \mathrm{c}$ & $3,71 \mathrm{a}$ \\
\hline & 6 & $84,5 \mathrm{~b}$ & $9,88 \mathrm{c}$ & $3,58 \mathrm{a}$ \\
\hline CV (\%) & & 15,85 & 18,42 & 5,34 \\
\hline
\end{tabular}

Médias seguidas de mesma letra minúscula na coluna não diferem estatisticamente entre si, ao nível de 5\% de probabilidade, pelo teste de Tukey.

$\mathrm{SP}=$ semente sem polpa; $\mathrm{CP}=$ sementes com polpa; $\mathrm{LT}=$ sementes lavadas e tratadas com hipoclorito.

TABELA 2 - Porcentagem, tempo e índice de velocidade de germinação das sementes de camu-camu e sua interação com ambiente, período de armazenamento e formas de conservação. Manaus - AM.

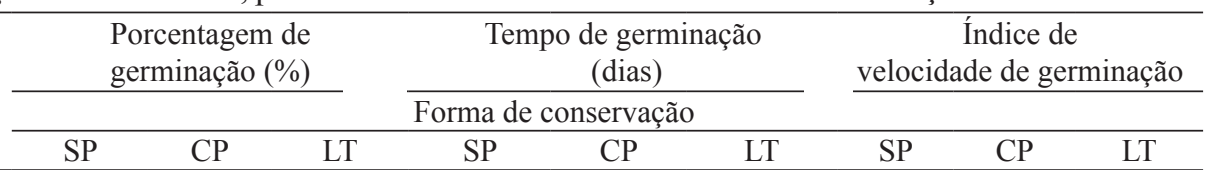

Natural 94,3 abA 97,8 a A 96,3 ab A 31,80 b A 33,15 a A 32,54 b A 2,35 b A 2,25 b A 2,53 c A

Ambiente de Água 97,3 a A 97,5 a A 98,0 a A 24,64 c A 17,28 c B 15,82 c B 3,55 a A 3,67 a A 3,79 a A armazenamento $5^{\circ} \mathrm{C} \quad 92,3 \mathrm{ab}$ A 46,8 c B 91,5 bc A 32,10 b A 26,62 b A 31,53 b A 2,62 b A 0,50 d B 2,86 b A $10^{\circ} \mathrm{C} 91,0$ b A 73,5 b B 89,0 c A 43,87 a A 32,94 ab B 41,59 a A 1,93 c A 1,11 c B 1,83 d A

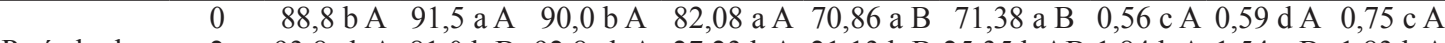

Período de 293,8 ab A 81,0 b B 92,8 ab A 27,23 b A 21,13 b B 25,35 b AB 1,84 b A 1,54 c B 1,83 b A armazenamento 498,8 a A $74,3 \mathrm{c}$ B 97,8 a A 11,79 c A 10,07 c A 14,33 c A 4,08 a A 2,93 a B 4,13 a A 693,5 ab A 65,8 d B 94,3 ab A 11,30 c A 7,92 c A 10,43 c A 3,96 a A 2,47 b C 4,30 a B

Médias seguidas de mesma letra minúscula na coluna e maiúscula na linha não diferem estatisticamente entre si, ao nível de 5\% de probabilidade, pelo teste de Tukey.

$\mathrm{SP}=$ semente sem polpa $\mathrm{CP}=$ sementes com polpa; $\mathrm{LT}=$ sementes lavadas e tratadas com hipoclorito. 
TABELA 3 -Porcentagem, tempo e índice de velocidade de germinação das sementes de camu-camu, nteração com ambiente com período de armazenamento, obtidas no ensaio de longevidade e armazenamento, Manaus, 2005.

\begin{tabular}{|c|c|c|c|c|c|c|c|c|c|c|c|c|}
\hline \multirow{3}{*}{$\begin{array}{c}\text { Ambiente } \\
\text { de } \\
\text { Armazenaento }\end{array}$} & \multicolumn{4}{|c|}{ Germinação de semente (\%) } & \multicolumn{4}{|c|}{$\begin{array}{l}\text { Tempo de germinação semente } \\
\text { (dias) }\end{array}$} & \multicolumn{4}{|c|}{$\begin{array}{l}\text { Índice de velocidade de } \\
\text { germinação }\end{array}$} \\
\hline & \multicolumn{12}{|c|}{ Período de armazenamento (mês) } \\
\hline & 0 & 2 & 4 & 6 & 0 & 2 & 4 & 6 & 0 & 2 & 4 & 6 \\
\hline Natural & $88,3 \mathrm{aB}$ & $92,7 \mathrm{bB}$ & 99,7 a A & $*$ & $81,58 \mathrm{a}$ & 8,31 & $10,05 \mathrm{bC}$ & $*$ & 0,46 & 0 & $82 \mathrm{bA}$ & $*$ \\
\hline Água & $90,7 \mathrm{aB}$ & $99,7 \mathrm{aA}$ & 100 a A & 00 a $\mathrm{A}$ & $56,67 \mathrm{t}$ & 0,16 & $5,20 \mathrm{bB}$ & $4,96 \mathrm{bH}$ & $30,92 \mathrm{a}$ & 71 & 56 & $49 \mathrm{aA}$ \\
\hline $5^{\circ} \mathrm{C}$ & $90,0 \mathrm{aA}$ & $80,0 \mathrm{cB}$ & $76,7 \mathrm{c} \mathrm{B}$ & $0,7 \mathrm{c} \mathrm{C}$ & 81,51 a & 2,04 & $10,88 \mathrm{bC}$ & $5,90 \mathrm{bc}$ & 0,56 & ,46 & 02 & $92 \mathrm{bA}$ \\
\hline $10^{\circ} \mathrm{C}$ & $91,3 \mathrm{aA}$ & $84,3 \mathrm{cB}$ & $84,7 \mathrm{~b} \mathrm{~B}$ & $77,7 \mathrm{bC}$ & $79,34 a$ & 7,77 & $22,14 \mathrm{aC} 1$ & $18,63 \mathrm{aC}$ & 0,60 & $38 \mathrm{~b}$ & $45 \mathrm{dA} 2$ & 07 c B \\
\hline
\end{tabular}

Médias seguidas de mesma letra minúscula na coluna e maiúscula na linha não diferem estatisticamente entre si, ao nível de 5\% de probabilidade, pelo teste de Tukey.

$\mathrm{SP}=$ semente sem polpa; $\mathrm{CP}=$ sementes com polpa; $\mathrm{LT}=$ sementes lavadas e tratadas com hipoclorito. * Não tem dados, porque estava germinado $100 \%$ antes do tempo.

\section{CONCLUSÕES}

1-O armazenamento em sacos de plástico, com umidade de sementes de camu-camu entre 45 e $56 \%$, não afeta na germinação de plântulas durante seis meses.

2-Sementes sem polpa e sementes lavadas / tratadas com hipoclorito, armazenadas em água até seis meses ou em ambiente natural até quatro meses, apresentam germinação acima de $90 \%$.

3-O armazenamento de sementes submersas em água proporciona maior porcentagem de germinação, menor tempo de germinação e maior índice de velocidade de germinação, em todos os períodos.

\section{REFERÊNCIAS}

AGUIAR, I.B.; RODRIGUES, F.C.M.P.; FIGLIOLIA, M.B. Sementes florestais tropicais. Brasília: ABRATES, 1993. 350 p.

ANDRADE, A.C.S.; PEREIRA, T.S. Comportamento de armazenamento de sementes de palmiteiro (Euterpe edulis Mart.). Pesquisa Agropecuária Brasileira, Brasília, v.32, n.10, p.987-991, 1997.

ANDRADE, J.S.; ARAGÃO, C.G.; GALEAZZI, M.A.M.; FERREIRA, S.A.N. Changes in the concentration of total vitamin $\mathrm{C}$ during maturation and ripening of camu-camu (Myrciaria dubia (H.B.K.) Mc Vaugh) Fruits cultivated in the upland of Brasilian Central Amazon. Acta Horticulturae, Wageningen, n. 370, p.177-180, 1995.
BRASIL. Ministério da Agricultura e Reforma Agrária. Regras para análise de sementes. Brasília, 1992. $365 \mathrm{p}$.

CALZADA, B. J.C.; RODRÍGUEZ, R.J. Investigaciones sobre el camu-camu (Myrciaria paraensis Berg). Iquitos: INIA, 1979/80. 15 p.

CORREA, S.I. Cultivo de camu-camu Myrciaria dubia H.B.K. na região de Loreto. Iquitos : INIA, 2000. $32 \mathrm{p}$.

FERREIRA, S.A.N.; GENTIL, D.F.O. Armazenamento de sementes de camu-camu (Myrciaria dúbia) com diferentes graus de umidade e temperaturas. Revista Brasileira de Fruticultura, Jaboticabal, v.25, n.3, p.440-442, 2003.

GENTIL, D.F.O.; FERREIRA, S.A.N. Tolerância a Dessecação e Viabilidade de Sementes de camucamu. Revista Brasileira de Fruticultura, Jaboticabal, v.22, n.2, p. 264-267, 2000.

GOMES, F.P. Curso de estatística experimental. Piracicaba: Escola Superior Luiz de Queiroz, USP, 1982. $466 \mathrm{p}$.

HONG, T.D.; ELLIS, R.H. A protocol to determine seed storage behavior. Roma: International Plant Genetic Resources Institute,1996. (Technical Bulletin, 1).

MAGUIRE, J.D. Speed of germination : and in selection and evaluation for seedling emergence and vigour. Crop Science, Madison, v.2, n.3, p. 176-177, 1962. 
ROCA, N.A. Estudio químico-bromatológico de la Myrciaria paraensis Berg. 1965. 51f. Thesis (Doctor's) - Facultad de Química, Univers. Nacional Mayor de San Marcos, Lima, 1965.

ROBERTS, E.H. Predicting the storage life of seeds. Seed Science and Technology, Zurich, v.1, p.499514, 1973.
VILLACHICA, H. EI cultivo del camu-camu (Myrciaria dubia (H.B.K.) Mc Vaugh) en la Amazonia Peruana. Lima: Secretaria Tempore, 1996. 95p. (El Tratado de Cooperación Amazônica)

YUYAMA, K.; AGUIAR, J.P.L.; YUYAMA, L.K.O. Camu-camu: um fruto fantástico como fonte de vitamina C. Acta Amazônica, Manaus, v.32, n.1, p.169-174, 2002. 